Artigos

Volume 7 - 2017| n. 11

\title{
A Implantação do Campus Campo Largo como Política Pública e as Implicações Orçamentárias como Sinalizadoras da Forma de Atuação do Estado
}

\section{Resumo}

O presente artigo se dedica a identificar algumas relações que se dão entre a implantação do campus Campo Largo do Instituto Federal do Paraná como política pública e as implicações orçamentárias como sinalizadoras da forma de atuação do Estado. Para tanto, este trabalho inicia destacando as políticas públicas como resultado das lutas e disputas que se dão no interior do Estado. Apresenta, em seguida, o processo de criação dos Institutos Federais de Educação, Ciência e Tecnologia como política pública com foco na consolidação do campus Campo Largo, por meio da análise da evolução na oferta de vagas, do número de servidores e dos recursos financeiros disponíveis desde sua criação até o ano de 2016. Os resultados deste trabalho apontam a interferência do desempenho econômico aliado ao contexto de embates que se dão no interior do Estado na implantação das políticas públicas e na consolidação dos campi dos Institutos Federais.

Palavras-chave: Estado. Políticas Públicas. Institutos Federais.

\section{The Implementation of the Campo Largo campus as a Public Policy and the Budgetary Implications as an Indication of the State's Way of Action}

\begin{abstract}
This article aims to identify some relationships between the implementation of the Federal Institute of Paraná Campo Largo campus as a public policy and the budgetary implications as a sign of the state's way of acting. This work begins by highlighting public policies as a result of the struggles and disputes within the state. Next, it presents the process of creation of the Federal Institutes of Education, Science and Technology as a public policy, focusing on the consolidation of Campo Largo campus by analyzing the evolution of vacancies number, the number of public servers and the available financial resources from its inauguration until 2016. The results point out the interference of the economic performance, related to the conflicts within the state in the implementation of public policies and the consolidation of the Federal Institutes campuses.
\end{abstract}

Keywords: State. Public Policies. Federal Institutes. 
A Implantação do Campus Campo Largo como Política Pública e as Implicações Orçamentárias como Sinalizadoras da Forma de Atuação do Estado

\section{Introdução}

Entender como se elaboram e se efetivam as políticas públicas exige analisá-las a partir da estrutura do Estado e, consequentemente, identificar os interesses e as disputas políticas que permeiam as relações na sociedade. Dessa forma, este artigo pretende, a partir da análise dos dados dos valores executados pelo campus Campo Largo, destacar algumas relações que implicam a concretização dos objetivos da implantação dos Institutos Federais e a definição dos recursos financeiros para essa política educacional.

As decisões que regulamentam o sistema de tributação definem e explicitam a forma pela qual a sociedade arrecada tributos e destina os recursos deles oriundos. Tais decisões são políticas porque estão permeadas de interesses e disputas que envolvem as obrigações que cada cidadão tem com o Estado em termos de contribuição, e também as definições das ações estatais a respeito do financiamento de políticas públicas. Sendo assim, este artigo inicia com uma breve explicitação sobre a relação do Estado com a formulação e implantação de políticas. Em seguida, analisa o contexto em que se deu a implantação dos Institutos Federais de Educação, Ciência e Tecnologia tendo como recorte o campus Campo Largo do Instituto Federal do Paraná.

Para este trabalho, foram analisados registros institucionais tais como editais, portarias, informações disponíveis em sites dos Institutos Federais, levantamento de dados realizados pela Secretaria Acadêmica, pela Seção Gestão de Pessoas e pela Direção Administrativa do campus Campo Largo.

\section{O Instituto Federal de Educação, Ciência e Tecnologia como política pública para a Educação Profissional}

As demandas e as conquistas sociais se dão num contexto de disputa em que concepções de sociedade e de justiça, relações entre classes heterogêneas e interesses públicos e privados estão em conflito. O governo, por meio de políticas públicas, toma determinado direcionamento político, de acordo com seu projeto de atuação e a concepção de Estado adotada ${ }^{1}$. No entanto, nem sempre os resultados são coerentes com o que se propõe, uma vez que o processo de execução envolve diversos agentes que também têm suas concepções e acabam interferindo durante as etapas de concretização de determinada ação governamental.

Poggi (1981) destaca que o Estado Moderno configura-se como uma estrutura administrativa complexa e planejada, distante de desenvolver-se de forma espontânea.

Finalmente, o Estado está internamente estruturado como uma organização formal e complexa. Compõe-se de órgãos - isto é, de loci interdependentes, mas nunca inteiramente autônomos para decidir, controlar e executar as diretrizes políticas cujas esferas de competência, cujos recursos e cujas modalidades de funcionamento são

1 Estado, escrito com inicial minúscula, refere-se a uma unidade administrativa estabelecida por uma subdivisão de um país. Estado, escrito com inicial maiúscula, refere-se (sem entrar na discussão das diferentes concepções que lhe conferem diferentes sentidos) a uma entidade constituída por um conjunto de instituições, que exerce um poder soberano sobre um povo e um território. Governo é uma das instituições do Estado que por meio de diversos órgãos e atividades exerce a ação política-administrativa. 
A Implantação do Campus Campo Largo como Política Pública e as Implicações Orçamentárias como Sinalizadoras da Forma de Atuação do Estado

determinados desde fora por outros órgãos hierarquicamente superiores (até se atingir um que tem sobre si a autoridade suprema). Cada órgão, por seu turno, é constituído como um conjunto de cargos diferenciados e complementares, em sua grande maioria hierarquicamente organizados. A ocupação desses cargos é regulamentada por critérios universalistas que, por sua vez, atribuem ao ocupante poderes e responsabilidades de natureza 'pública', impessoal e não possessória. A competição pelo poder político e o seu exercício numa sociedade constituída como Estado moderno envolvem tipicamente a busca e o preenchimento de 'cargos', e o exercício de influência sobre o seu funcionamento. (Note-se que a 'influência', por sua própria natureza, dificilmente pode ser distribuída e aplicada de acordo com termos universalistas.) Os cargos operam normalmente por referência a critérios de decisão e padrões de execução publicamente sancionados, não por recurso a justificações ad hoc (POGGI, 1981, p. 107).

A institucionalização, no interior das sociedades ocidentais modernas, da separação entre o público e o privado, o social e o político impulsionou, segundo Poggi (1981), o desenvolvimento do Estado Moderno.

Nicos Poulantzas (1985), filósofo e sociólogo grego, ao analisar a materialidade do Estado e o poder que este exerce como aparelho numa perspectiva marxista, salienta que essa materialidade não pode ser reduzida em sua tarefa de dominação política, mas sim através das relações de produção e a divisão social do trabalho. Nesse contexto, o Estado compõe o conjunto do campo de lutas (POULANTZAS, 1985). Essas lutas configuram o pano de fundo do processo de formação de demanda, elaboração e execução de políticas públicas em que se dá a articulação de interesses do Estado, do capital e da sociedade. O processo decisório relativo às políticas públicas assume direções diversas de acordo, portanto, com a concepção de Estado presente.

Ao tratar da ação do pessoal do Estado em sua constituição, Poulantzas (1985) afirma que a luta de classes está presente e interfere nos posicionamentos políticos o que impede que a ação do Estado seja neutra. A ausência da neutralidade revela-se, pois, na ação política, em que interesses diversos se confrontam. Ainda segundo Poulantzas (1985, p. 169):

Mais particularmente o poder político, cujo referencial é fundamentalmente o Estado, relaciona-se com a organização de poder de uma classe e a posição de classe na conjuntura (entre outros fatores, organização em partido), com as relações de classes constituídas como forças sociais, logo com um campo estratégico propriamente falando. O poder político de uma classe, sua capacidade de concretizar seus interesses políticos, depende não apenas de seu lugar (de sua determinação) de classe em relação às outras, mas também de sua posição e estratégia diante delas, o que denominei como estratégia do adversário.

Nesse sentido, as políticas públicas são permeadas por diversos fatores, incluindo a estrutura e o funcionamento do Estado e sua relação com o capital, com as relações de poder entre os agentes estatais, incluindo aí políticos e burocratas, bem como seus vínculos e posicionamentos diante dos problemas a serem resolvidos que demandaram determinada ação e à capacidade técnica de resolvê-los. 
A Implantação do Campus Campo Largo como Política Pública e as Implicações Orçamentárias como Sinalizadoras da Forma de Atuação do Estado

Os processos de tomada de decisões e de formulação e implantação de políticas públicas implicam elementos que vão desde a formulação legal de constituição de direitos dos cidadãos e deveres do Estado, passam pelo financiamento público e terminam na configuração da sociedade e a relação entre esta e os poderes públicos. Nesse contexto, as políticas públicas são ações que buscam solucionar problemas apresentados pela sociedade constituída por diferentes interesses, necessidades e ideologias, composta por diversos grupos, classes e instituições. O Estado, como campo de lutas e disputas oriundas dessa diversidade, também intervém de forma conflitiva, o que se reflete na construção de sua ação e em seu funcionamento, as contradições e os consensos presentes na sociedade.

As políticas públicas configuram-se como formas de ação governamental diante de diferentes demandas, tais como as da área da educação. Essas formas de ação são resultado de pressões de diferentes segmentos da sociedade e do campo de disputa inerente aos processos políticos de decisão que demarcarão, entre os diversos problemas a serem resolvidos, as prioridades que podem ser identificadas através da análise dos seus objetivos, da estrutura e abrangência da política, da aplicação de recursos públicos, das estratégias de implementação, dos recursos humanos entre outros fatores específicos de cada área.

\begin{abstract}
Numa versão mais complexa e também crítica que considera os problemas decorrentes da estrutura econômica de classes da sociedade capitalista, baseada na valorização do capital privado e no trabalho assalariado, as políticas públicas podem ser compreendidas como estratégias de ação governamental que buscam compatibilizar as duas grandes fontes do Poder Público: os recursos econômicos provenientes do processo de produção e de acumulação privada do capital, obtidos, sobretudo por meio de impostos e tributações e que asseguram um dos elementos necessários para a produção de Políticas Públicas; e a legitimidade política dos poderes públicos, advinda quer dos pleitos eleitorais que autorizamos poderes públicos constituídos a agirem, pelo menos em regimes político-democráticos, quer das próprias políticas públicas. Nesse último caso, é a eficácia governamental para resolver problemas públicos por meio de políticas públicas a principal fonte de legitimação, uma vez que os governos são avaliados e julgados pela capacidade de conduzir a sociedade para níveis maiores de bem-estar e desenvolvimento econômico (MINCATO, 2012, p. 84, grifo da autora).
\end{abstract}

Nesse sentido, o poder público se manifesta diante dos problemas apresentados pela sociedade por meio de políticas públicas e precisa, para ter legitimidade, de eficácia no atendimento às demandas. Na sociedade capitalista, as políticas públicas são dependentes de recursos gerados pelo desenvolvimento econômico. A ação estatal, no campo social, está permeada pelas contradições desse sistema, que demandam os problemas a serem resolvidos, mas também oferecem meios para resolvê-los. Assim, por exemplo, os desafios de combate às desigualdades econômicas e sociais, têm sua solução possível através de políticas que serão financiadas por recursos dependentes de uma economia próspera.

Durante crises econômicas, porém, com menos recursos, o Estado revê suas ações a fim de enxugar os gastos públicos. No caso das políticas sociais o impacto é maior já que, além da escassez de recursos, os problemas sociais também se ampliam com a diminuição do poder aquisitivo e maiores taxas de desemprego.

No entanto, a melhora no desempenho econômico nem sempre significa ampliação de recursos financeiros em políticas públicas voltadas à área social. Ao analisar o financiamento da educação no Brasil por 21 anos, de 1964 a 1985, Melchior (1987, p. 5), atenta à necessidade de clareza de valores e empenho da esfera política: 
A Implantação do Campus Campo Largo como Política Pública e as Implicações Orçamentárias como Sinalizadoras da Forma de Atuação do Estado

O financiamento, em todas as esferas de atividades, também depende do funcionamento adequado do sistema econômico. Assim como valores claros e vontade política legítima são indispensáveis, o grau de atividade do sistema econômico acaba expressando maior ou menor possibilidade de financiar a ação para a eliminação dos problemas. Mas essa afirmação não significa dizer que o financiamento da Educação está na dependência de ritmos crescentes do crescimento econômico. Por não termos valores claros e vontade política derivada do universo político, e sim do universo tecnoburocrático, assistimos nestes 21 anos a uma reativação do sistema econômico que não beneficiou o sistema social e, neste, incluída a Educação. Ao contrário do que costuma acontecer na maioria dos países, foi durante o período de maior crescimento do PIB que verificamos uma decrescente aplicação de recursos financeiros em Educação, principalmente pela esfera federal, que é aquela que maior potencialidade apresenta na perspectiva de receita fiscal efetivamente arrecadada.

As prioridades de investimento do orçamento público dependem, portanto, dos interesses que prevalecem no jogo político, que tanto em momentos de crises ou recessões econômicas quanto de prosperidade fazem as escolhas que definem para onde se destinam os maiores e menores volumes de recursos.

A Constituição Federal de 1988 (BRASIL, 1988), ampliou o sistema de políticas sociais. Os direitos sociais foram desvinculados do mercado de trabalho e se garantiu o direito à saúde, educação e assistência social. Com a promulgação da Constituição de 1988, o Estado assume a responsabilidade pela proteção social, vinculando o direito social à condição de cidadania. No entanto, a efetivação de políticas sociais não ocorre de maneira automática, mas depende do reconhecimento dos direitos sociais. A implementação dos direitos sociais declarados na Constituição de 1988 demandam constante embate com setores conservadores da sociedade e, diante de crises, sofrem a ameaça dos cortes orçamentários.

Dessa forma, a pobreza e a desigualdade econômica e social ainda são marcas da sociedade brasileira. Os serviços públicos ainda são insuficientes e demandam mais qualidade. Nesse aspecto, a forma como se constitui a carga tributária e o gasto público revela o papel assumido pelo Estado na superação desses problemas que assolam historicamente o país.

Políticas públicas dependem de definições que envolvem financiamento, abrangência, enfim, critérios que vão moldando o que de início era uma proposta. Em educação, há historicamente, a luta pela democratização do acesso, permanência e sucesso escolar para a Educação Básica (Educação Infantil, Ensino Fundamental e Ensino Médio). O debate sobre o direito à educação é ampliado, atualmente, pela discussão sobre a qualidade da educação, o atendimento às diferenças e a ampliação da obrigatoriedade abrangendo o Ensino Médio. Nessa perspectiva, a necessidade de recursos financeiros cresce. Porém, diante da crise, o que se tem são contingenciamentos e congelamentos de recursos para a área social, entre as quais a educação. Então, posterga-se, no âmbito da ação estatal, o processo de ampliação de direitos.

Analisando as prioridades do Estado brasileiro, a partir da verificação da utilização dos recursos orçamentários, Salvador e Teixeira (2014, p. 19), concluem que:

[...] a despesa que mais compromete as contas públicas brasileira são as despesas financeiras referentes ao pagamento de juros e amortização da dívida. O dilema do orçamento público no Brasil não se encontra na dicotomia despesas de investimento versus custeio. Ambas são fundamentais e necessárias para o desenvolvimento 
A Implantação do Campus Campo Largo como Política Pública e as Implicações Orçamentárias como Sinalizadoras da Forma de Atuação do Estado

econômico e social do país. A questão central é se o Brasil vai continuar refém dos rentistas do capital financeiro ou vai priorizar a construção de um sistema de proteção social, com expansão de investimentos. As despesas com saúde e educação estão abaixo dos padrões internacionais dos países da Organização para a Cooperação e Desenvolvimento Econômico (OCDE). Assim como nos últimos anos não foram priorizadas no orçamento público, as despesas e os investimentos necessários para universalização das políticas sociais.

Nesse sentido, a ação do Estado brasileiro não prioriza as políticas sociais, entre as quais a educação, em detrimento da esfera econômico-financeira. Isto é, investe a maior parte dos recursos orçamentários na área econômico-financeira, envolvendo pagamento de juros, encargos e amortização da dívida pública.

Diante disso, a análise e avaliação de políticas públicas se torna baliza para a observância da lei, para o alinhamento das ações do Estado com a perspectiva da formação cidadã e para a necessidade da ampliação do direito.

No caso das políticas de Ensino Médio integrado à educação profissional é preciso superar a concepção de preparação apenas para as demandas do mercado. Definido como última etapa da Educação Básica pela Lei de Diretrizes e Bases (BRASIL, 1996), e tendo como função, ainda de acordo com esta lei, tanto a "[...] consolidação e o aprofundamento dos conhecimentos adquiridos no ensino fundamental" (BRASIL, 1996, art. 35) quanto "[...] a preparação básica para o trabalho e a cidadania" (BRASIL, 1996, art. 35), o Ensino Médio deve ofertar um ensino que proporcione não só conhecimentos técnicos quando integrado à educação profissional, mas também que ofereça ao estudante condições para reconhecer-se como sujeito da história, analisar o contexto em que nossa sociedade está inserida bem como compreender o mundo do trabalho e adaptar-se às mudanças que ocorrem devido aos avanços tecnológicos e às novas formas de organização do trabalho. Entender esses aspectos e procurar analisá-los criticamente são práticas que desenvolvem no indivíduo melhores condições para exercer sua cidadania.

Com esta concepção de educação, são criados, através da Lei n 11.892/08 (BRASIL, 2008), os Institutos Federais de Educação, Ciência e Tecnologia especializados na Educação Profissional e Técnica. Os Institutos Federais fazem parte da política educacional do governo federal em que a educação profissional está alinhada com as políticas de inclusão, tais como formas de ingresso diferenciadas nos cursos de nível Médio Integrado e cursos subsequentes e Ensino Superior, por meio de quotas para alunos de escola pública, de baixa renda, pessoas com deficiência, indígenas e afrodescendentes. Os processos seletivos não necessitam ocorrer obrigatoriamente através de provas, mas também por sorteios. São ofertadas bolsas acadêmicas e auxílios estudantis que se alinham às políticas de inclusão, possibilitando, além do ingresso, a permanência do estudante na escola. Além disso, os Institutos Federais contam com professores com alto nível de formação e dedicação exclusiva, com estrutura que vai se tornando atrativa (laboratórios, recursos didáticos) e articulação entre ensino, pesquisa e extensão.

Em síntese, esse novo desenho constituído traz como principal função a intervenção na realidade, na perspectiva de um país soberano e inclusivo, tendo como núcleo para irradiação das ações o desenvolvimento local e regional. O papel que está previsto para os Institutos Federais é o de garantir a perenidade das ações que visem a incorporar, antes de tudo, setores sociais que historicamente foram aliados dos processos de 
A Implantaçao do Campus Campo Largo como Política Pública e as Implicações Orçamentárias como Sinalizadoras da Forma de Atuação do Estado

desenvolvimento e modernização do Brasil. Tal desafio legitima e justifica a importância de sua natureza pública e afirma uma educação profissional e tecnológica como instrumento realmente vigoroso na construção e no resgate da cidadania e da transformação social (PACHECO, 2011, p. 20).

Diante do desafio proposto de ser uma instituição que oferta um ensino que promova a formação integral dos estudantes e que atua para impulsionar o desenvolvimento da região em seu entorno, os Institutos Federais estão espalhados pelo país numa perspectiva de interiorização e verticalização do ensino. São 38 Institutos Federais distribuídos em todos os estados, totalizando mais de seiscentos campi que ofertam cursos de qualificação, ensino médio integrado, cursos superiores de tecnologia e licenciaturas e pós-graduação.

A Lei $n^{\circ} 11.892 / 2008$ (BRASIL, 2008) define a distribuição da oferta de vagas da seguinte forma: $50 \%$ para atender os cursos técnicos, priorizando a forma integrada com o ensino médio; pelo menos $20 \%$ para os cursos de licenciatura, especialmente nas áreas de ciências, matemática e educação profissional; e 30\% podem ser destinados a cursos superiores de tecnologia, cursos de bacharelado e engenharia, cursos de pós-graduação lato sensu e cursos de pós-graduação stricto sensu.

\section{O Campus Campo Largo: o desafio de consolidar-se diante das imposições da crise econômica no orçamento}

O Instituto Federal do Paraná (IFPR) está presente em vários municípios do estado (Figura 1). São 25 campi que ofertam cerca de 80 cursos entre os técnicos de nível médio, cursos superiores e de pós-graduação. O IFPR oferta também cursos de Formação Inicial e Continuada (FIC), cursos PROEJA, entre outros.

Figura 1 - Campi do IFPR

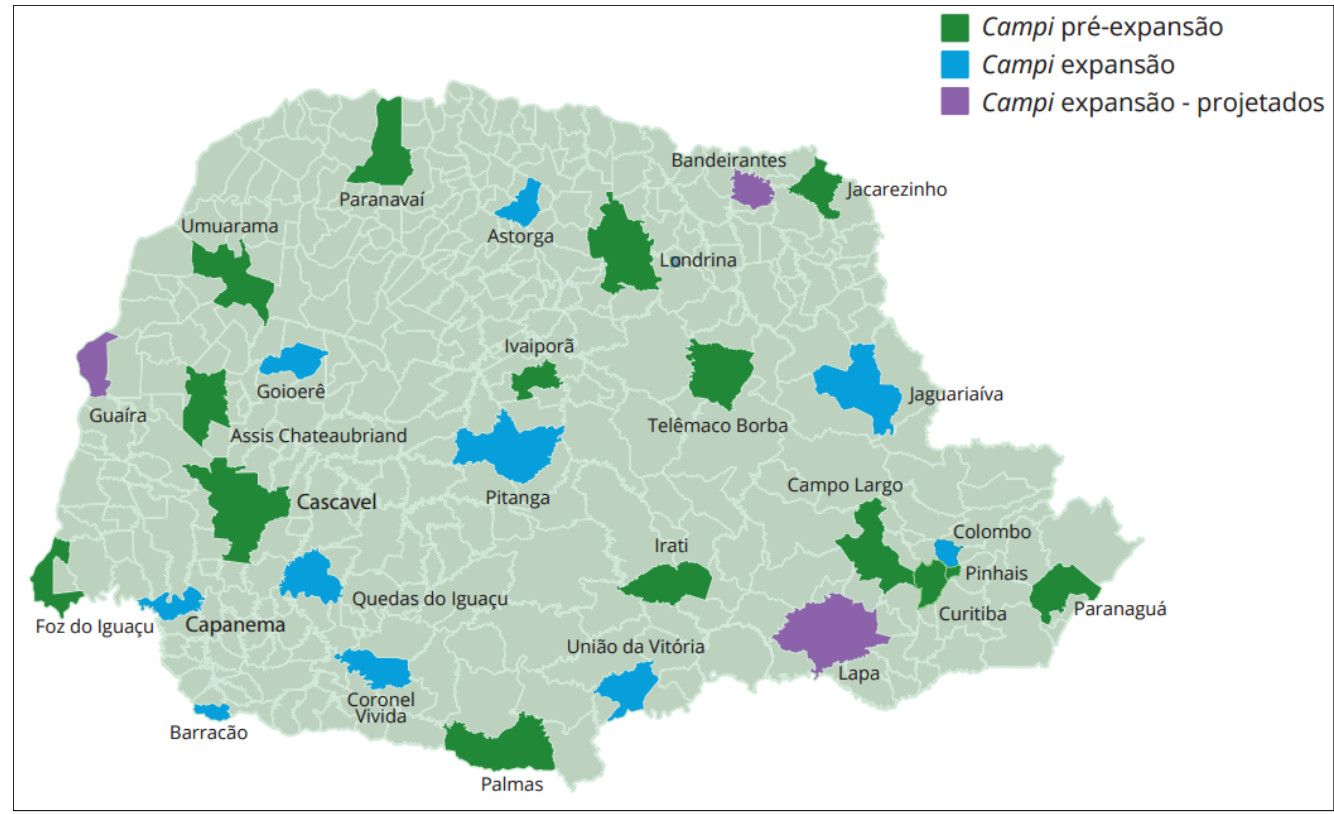

Fonte: Instituto Federal do Paraná (2017).

Em 2009 foi firmada uma parceria entre o Instituto Federal do Paraná e a prefeitura de Campo Largo, município da Região Metropolitana de Curitiba, onde foi instalado um Núcleo Avançado do campus Curitiba que passou a ofertar cursos técnicos para atender as 
A Implantação do Campus Campo Largo como Política Pública e as Implicações Orçamentárias como Sinalizadoras da Forma de Atuação do Estado

demandas de qualificação profissional da região. As atividades de ensino, administrativas e financeiras eram, portanto, vinculadas ao campus Curitiba, com professores e demais funcionários lotados naquele campus.

O quadro de servidores lotados no Núcleo Avançado começou a se formar a partir da realização de concurso público em 2010. Em junho do referido ano foram selecionados os professores, e os técnicos administrativos em agosto. A prefeitura doou uma área de cerca de trinta e quatro mil metros quadrados com prédios que abrigavam uma indústria cerâmica (Cerâmica Iguaçu) e reformou um dos barracões. No entanto, essa reforma demandava tempo e, por isso, o início das atividades desse Núcleo Avançado aconteceu no período noturno na Escola Municipal Reino da Loucinha, que oferta Educação Infantil e anos iniciais do Ensino Fundamental. Assim, em 24 de maio de 2010 iniciaram-se os cursos técnicos na forma subsequente em: Agroecologia, Eletrotécnica e Mecânica. Os cursos funcionavam na modalidade presencial, sendo ofertadas 120 vagas, divididas em 40 vagas para cada curso.

Dessa forma, a estrutura utilizada para as aulas eram três salas de aula em 2010, seis em 2011 e um laboratório de informática utilizado para atividades administrativas. Em agosto daquele mesmo ano, foram ofertados no Colégio Estadual Macedo Soares, escola localizada há poucos metros da escola municipal, os cursos técnicos em Administração e Secretariado na modalidade a distância. Nesta mesma modalidade, e também no mesmo colégio estadual, foram ofertados os cursos técnicos em Eventos, Logística, Meio Ambiente e Segurança do Trabalho em agosto de 2011. O Núcleo Avançado foi transferido para a nova sede em setembro de 2011. No dia cinco de dezembro de 2012 ganhou status de campus, em solenidade no Ministério da Educação, em Brasília.

Para que haja a compreensão da relação entre a dinâmica da disponibilidade de recursos financeiros do campus com sua consolidação enquanto instituição de ensino se faz necessário fazer um breve histórico da oferta de cursos, número de estudantes e servidores do campus. Como foi relatado anteriormente, em 2010 foram ofertadas 120 vagas. Em 2011 e em 2012 foram ofertados os mesmos cursos com, também, 120 vagas no total.

Em 2013, iniciou-se a oferta de cursos no período diurno para os cursos de Eletrotécnica e Mecânica que passaram a ofertar 64 vagas cada um, divididas igualmente entre período matutino e noturno. O curso de Agroecologia não disponibilizou vagas, visando uma reestruturação. Nesse mesmo ano foram ofertadas 20 vagas para um novo curso técnico subsequente noturno: Cerâmica. Este curso procura atender a uma de suas funções que é o desenvolvimento social e econômico local. A cidade de Campo Largo é conhecida como "Capital da Louça", pois é um polo de destaque na produção de cerâmica além de ser uma região que oferece recursos naturais destinados a essa atividade. No total, portanto, foram ofertadas 148 vagas em 2013.

No ano de 2014 o número de vagas ofertadas foi ampliado para 225 assim distribuídas: 80 para o curso técnico subsequente em Eletrotécnica (40 vagas para cada período), 80 para o curso técnico subsequente em Mecânica (40 vagas para cada período), 50 para o curso técnico subsequente em Cerâmica para o turno da noite, a fim de se abrir mais uma turma no segundo semestre. Porém, como a demanda de estudantes foi baixa, foi aberta somente a turma do primeiro semestre e, por isso, nesse estudo serão consideradas apenas as 25 vagas abertas para o primeiro semestre. A partir de 2014, o campus Campo Largo passou a ofertar 
A Implantação do Campus Campo Largo como Política Pública e as Implicações Orçamentárias como Sinalizadoras da Forma de Atuação do Estado

o curso técnico em Eletromecânica Integrado ao Ensino Médio, com 40 vagas para o período matutino.

No ano seguinte, 2015, os cursos técnicos subsequentes em Eletrotécnica e Mecânica ofertaram 64 vagas cada, distribuídas igualmente para os dois turnos de atuação, e o curso subsequente técnico em Cerâmica mais 32 vagas para o período noturno. Já o curso técnico em Eletromecânica Integrado ao Ensino Médio ofertou 40 vagas para o período matutino. 0 número total de vagas diminuiu, portanto, para 200.

Em 2016, houve a ampliação da oferta de mais um curso técnico subsequente noturno: Administração, e mais um curso técnico integrado ao Ensino Médio: Automação Industrial, ofertado no período vespertino. Foram ofertadas 40 vagas para cada turma, sendo duas turmas para os cursos técnicos subsequentes em Eletrotécnica e Mecânica (uma de cada curso para o período noturno e outra para o período matutino), uma turma para os cursos técnicos subsequentes em Cerâmica e Administração (uma turma para cada curso no período noturno) e uma turma para cada curso de Ensino Médio Integrado - Eletromecânica e Automação Industrial - (duas turmas no período matutino), totalizando 320 vagas. No segundo semestre de 2016, o curso técnico subsequente em Agroecologia voltou a funcionar agora em período integral, no regime de organização curricular por alternância. Somam-se, então, mais 25 vagas ofertadas (Gráfico 1).

Gráfico 1 - Evolução da Oferta de Vagas no Campus Campo Largo/IFPR (2010-2016)

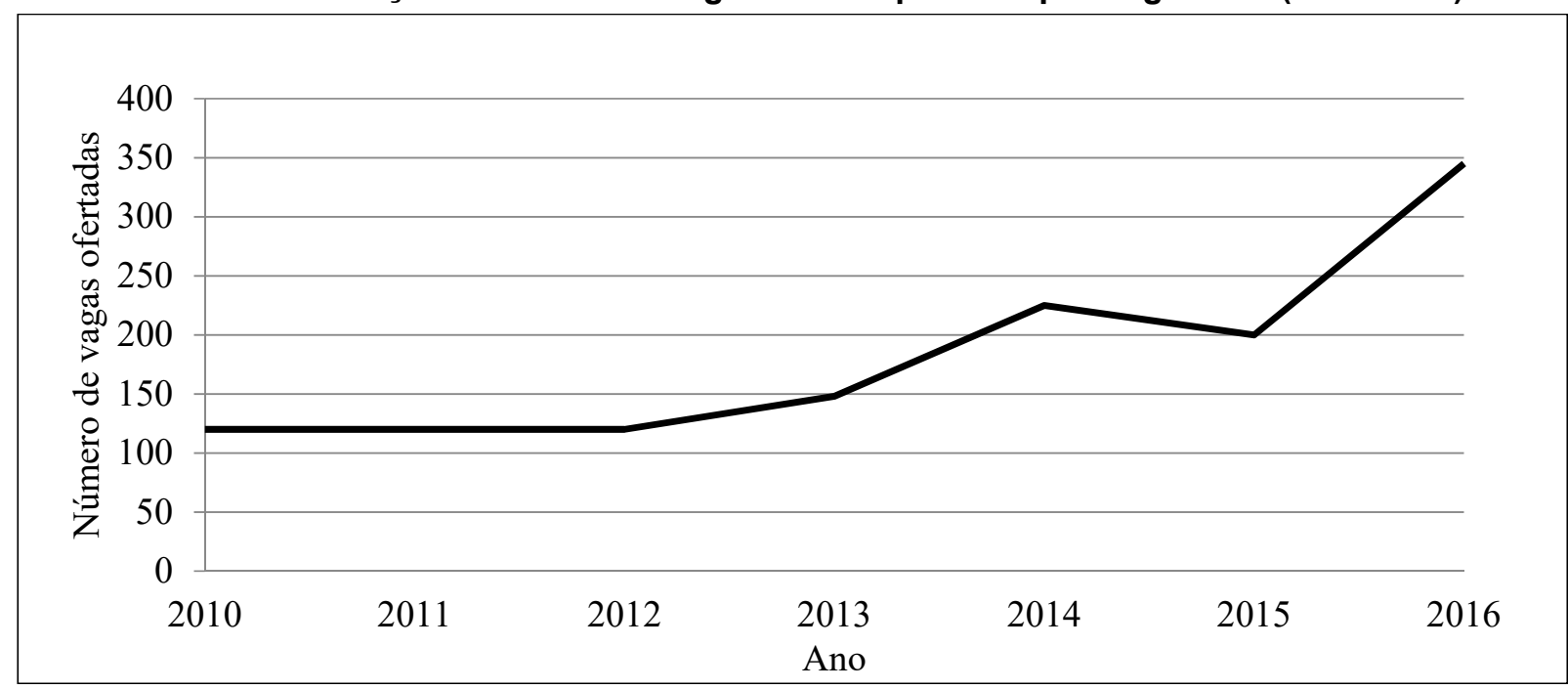

Fonte: Elaboração própria a partir de dados da Secretaria Acadêmica do campus.

O quadro de servidores do campus Campo Largo foi sendo ampliado conforme se dava sua consolidação, bem como o aumento do número de estudantes. Foram contabilizados para este trabalho os servidores que estavam atuando no campus, excluindo, portanto, os que estavam em afastamento integral para pós-graduação ou atuando em outro campus por meio de termo de cooperação entre campi. Os números, principalmente de docentes, são aproximados visto que há ingresso e saída de profissionais durante o ano letivo.

Em 2010 o campus contava com 3 técnicos administrativos e 5 professores. Em 2011 eram 8 técnicos administrativos e 18 professores. Em 2012 o número de servidores foi ampliado para 11 técnicos administrativos e 20 professores e em 2013 eram 13 técnicos administrativos e 28 docentes. Em 2014 o número de técnicos administrativos elevou-se para 
A Implantação do Campus Campo Largo como Política Pública e as Implicações Orçamentárias como Sinalizadoras da Forma de Atuação do Estado

28 e o de docentes para 32. Em 2015 eram 29 técnicos administrativos e 38 docentes. Em 2016 o quadro era composto por 29 técnicos administrativos e 44 docentes (Gráfico 2).

Gráfico 2 - Evolução do Número de Servidores no Campus Campo Largo/IFPR (2010-2016)

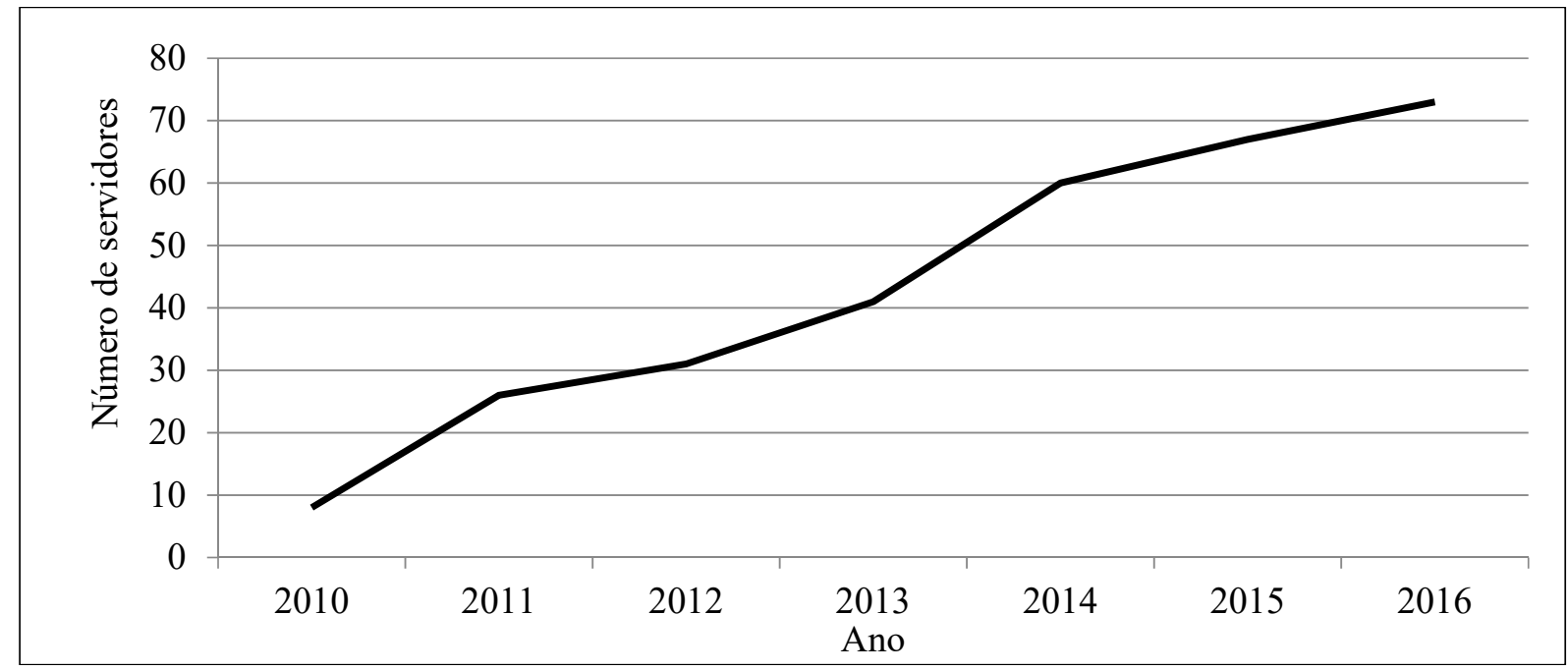

Fonte: Elaboração própria a partir de dados da Seção de Gestão de Pessoas do campus.

Com relação ao orçamento do campus é importante destacar que a Lei $n^{0} 11.892 / 08$, em seu artigo $9^{\circ}$, dispõe: "Cada Instituto Federal é organizado em estrutura multicampi, com proposta orçamentária anual identificada para cada campus e a reitoria, exceto no que diz respeito a pessoal, encargos sociais e benefícios aos servidores" (BRASIL, 2008, art. 9).

O Conselho Nacional das Instituições da Rede Federal de Educação Profissional, Científica e Tecnológica (CONIF), órgão representativo da rede, é composto pelos reitores dos institutos. Ao CONIF cabe, entre outras funções, avaliar a divisão do orçamento entre os institutos elaborado pelo Fórum de Planejamento e Administração da Rede Federal (FORPLAN) constituído por integrantes das pró-reitorias de Administração de todos os Institutos, CEFETs e Colégio Pedro II. Após aprovar, o CONIF encaminha o orçamento à Secretaria de Educação Profissional e Tecnológica (SETEC) para aprovação final. Para a distribuição financeira entre reitorias e os campi, o CONIF desenvolveu uma matriz orçamentária a partir de critérios técnicos.

Para demonstrar os valores executados pelo campus Campo Largo foram considerados, neste trabalho, os valores empenhados para o campus. Dessa forma, além do valor descentralizado empenhado pela unidade, há a soma de valores provenientes de recursos centralizados na Reitoria, tais como o Fundo de Desenvolvimento Institucional, a Ação 20 RG (destinada à expansão e reestruturação da Rede Federal de Educação Profissional e Tecnológica) e o Termo de Execução Descentralizada (TED).

Em 2010, a unidade de Campo Largo foi instalada como um Núcleo Avançado do campus Curitiba. Devido ao fato de ser um Núcleo Avançado e ter suas atividades iniciadas num prédio de uma escola municipal, a unidade de Campo Largo não teve orçamento próprio, nem despesas com materiais de consumo e equipamentos permanentes que foram supridas pelo campus Curitiba, ao qual suas atividades administrativas e financeiras estavam vinculadas. 
A Implantação do Campus Campo Largo como Política Pública e as Implicações Orçamentárias como Sinalizadoras da Forma de Atuação do Estado

Com orçamento próprio em 2011, o campus Campo Largo passa a executar seus recursos em despesas de custeio (gastos com pessoal, material de consumo e serviços) e em capital (gastos que envolvem a aquisição de materiais permanentes e equipamentos e também a execução de obras). Naquele ano, o valor empenhado para o campus foi de $\mathrm{R} \$$ 1.575.036,91. Em 2012 o valor empenhado foi elevado para $\mathrm{R} \$ 4.424 .829,70$. Destaca-se que, desse valor, $\mathrm{R} \$ 810.000,00$ foram destinados para reformar dois barracões da antiga Cerâmica Iguaçu, objetivando a constituição de um bloco de salas de aula e em um laboratório de Eletromecânica; e R $\$ 1.254 .574,75$ para empenhar $62,3 \%$ da primeira fase de construção do bloco administrativo. O restante foi destinado a despesas com custeio, aquisição de equipamentos e materiais permanentes. Para o ano de 2013 o campus Campo Largo teve como valor empenhado $\mathrm{R} \$ 3.795 .663,71$ que além de ter sido utilizado para despesas de custeio e capital teve $\mathrm{R} \$ 2.012 .847,80$ utilizados para empenhar o restante da primeira fase do bloco administrativo (37,7\% da obra).

Em 2014, o valor empenhado foi de $\mathrm{R} \$ 2.715 .449,96$. O destaque para a composição desse valor foi a despesa com recuperação do campus após uma chuva de granizo, que aconteceu em outubro daquele ano. Telhados, vidros e forros dos prédios do campus foram danificados sendo necessário recorrer ao Fundo de Desenvolvimento Institucional, que disponibilizou $\mathrm{R} \$ 645.657,67$. Ainda em 2014, foram utilizados recursos da Ação 20RG para o fechamento da estrutura pré-fabricada, acabamentos e instalações complementares do bloco administrativo, que também estão contabilizados no valor empenhado.

Segundo Oreiro (2017) a partir do segundo trimestre de 2014 inicia-se uma recessão econômica no país, caracterizada pela queda significativa na atividade econômica brasileira. O autor destaca, com base em dados do Ipeadata, que "[...] entre o segundo trimestre de 2014 e o terceiro trimestre de 2016, o PIB brasileiro apresentou uma queda de $8,33 \%$ " (OREIRO, 2017, p.75).

Com a consequente queda na arrecadação de impostos e contribuições federais as instituições da Rede Federal tiveram contingenciamentos de recursos. Em 2015, o valor empenhado foi de $\mathrm{R} \$ 2.506 .827,89$. No entanto, com o cancelamento da construção do ginásio de esportes, o valor de $\mathrm{R} \$ 597.500,00$ foi estornado.

Na previsão orçamentária do campus para 2016 já constava um contingenciamento no valor de $\mathrm{R} \$ 206.335,92$ para despesas centralizadas na Reitoria a fim de atender as necessidades financeiras de processo seletivo, SEPIN (Seminário de Extensão, Ensino, Pesquisa e Inovação do IFPR) e Jogos do IFPR. Naquele ano IFPR teve um contingenciamento de $30 \%$ no valor do orçamento previsto. Assim, o valor empenhado para o campus foi reduzido para $\mathrm{R} \$ 1.757 .222,00$ (Gráfico 3). 
A Implantação do Campus Campo Largo como Política Pública e as Implicações Orçamentárias como Sinalizadoras da Forma de Atuação do Estado

Gráfico 3 - Evolução dos Valores Executados pelo Campus Campo Largo/IFPR (2011-2016)

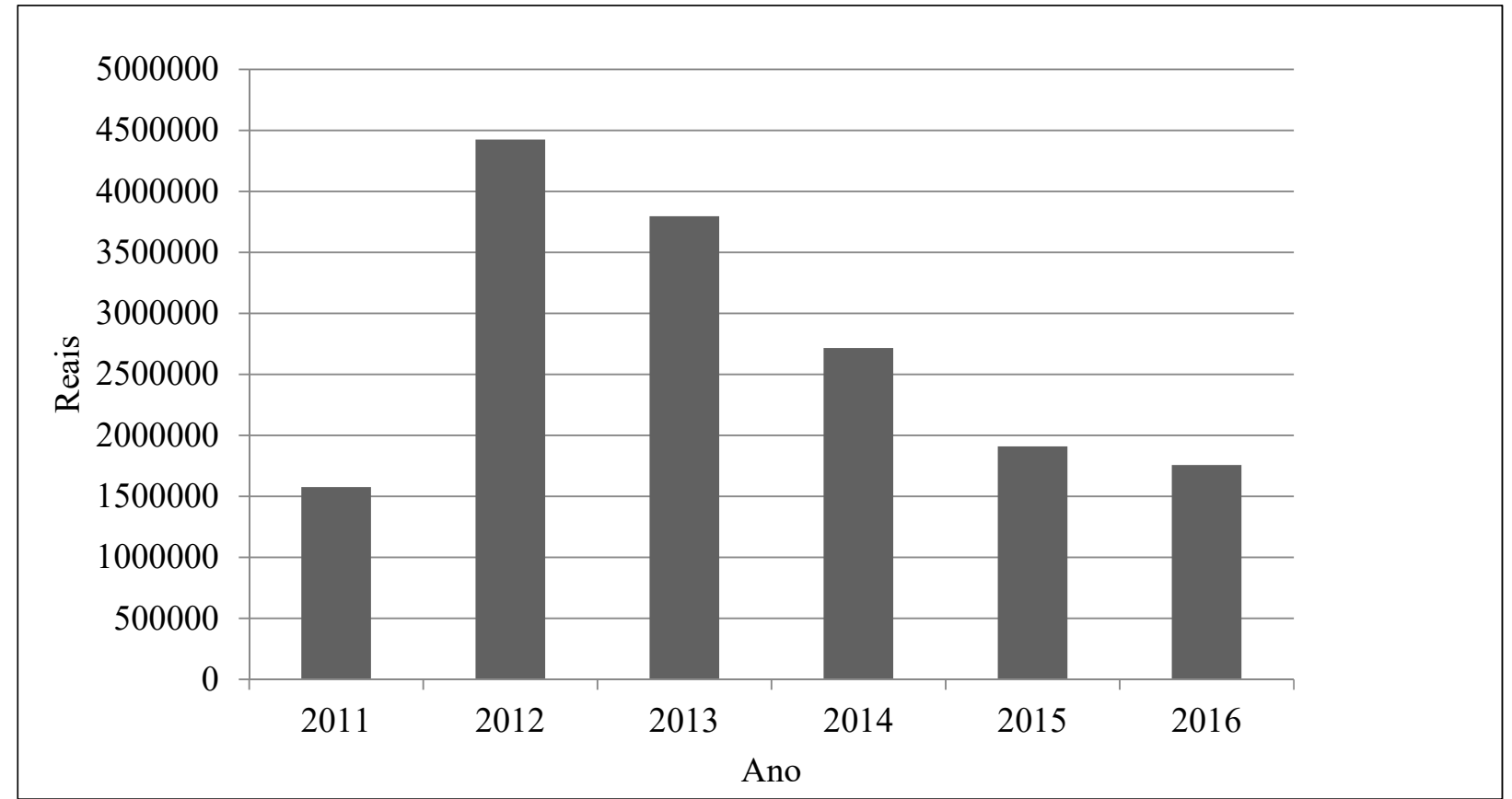

Fonte: Elaboração própria a partir de dados da Direção Administrativa do campus.

Segundo o documento Plano de Distribuição Orçamentária 2016 (INSTITUTO FEDERAL DO PARANÁ, 2016), o orçamento do Instituto Federal do Paraná cresceu até o ano de 2014. Nos anos seguintes, houve uma diminuição significativa dos recursos de capital na instituição devido a cortes na etapa definida como Expansão da Rede Federal (Ação 20RG) estipulados pela Secretaria de Educação Profissional e Tecnológica, do Ministério da Educação.

A diminuição dos recursos financeiros é resultado de ajustes no gasto público devido à crise econômica. Com a ampliação do número de campi e de estudantes matriculados nos Institutos Federais os efeitos dos cortes no orçamento dos Institutos Federais tornam-se, ano após ano, mais significativos. Dessa forma, após um período de grande expansão da Rede Federal impulsionada pela criação dos Institutos Federais, os contingenciamentos e cortes nos recursos financeiros passam a fazer parte das previsões orçamentárias.

No caso do campus Campo Largo, embora o campus já tivesse adquirido muitos equipamentos, ampliado o seu acervo bibliográfico e realizado algumas obras, os valores executados a partir de 2015 tornaram-se insuficientes para dar continuidade à ampliação da estrutura física para atender o número crescente de estudantes matriculados. Assim, os espaços foram adaptados: para a demanda de mais salas de aula foram utilizadas salas do bloco administrativo e as práticas esportivas ocorrem também num espaço adaptado anexo ao primeiro bloco reformado.

De 2011 a 2016, os valores dos recursos destinados ao custeio foram elevados a cada ano e representaram menores impactos nos valores executados. Foi dado destaque, neste trabalho, às despesas de capital porque foram os recursos a elas destinados que mais sofreram cortes e contingenciamentos no orçamento dos Institutos Federais, impactando na diminuição dos valores executados. Isso afetou a melhoria estrutural do campus comprometendo a concretização da excelência de ensino proposta por esta escola. Como 
A Implantação do Campus Campo Largo como Política Pública e as Implicações Orçamentárias como Sinalizadoras da Forma de Atuação do Estado

política pública, os Institutos Federais surgiram como possibilidade de acesso a uma formação inclusiva e de qualidade. No caso do campus Campo Largo, que ainda necessita de obras e reformas para que atenda com qualidade as demandas educativas, torna-se necessário o improviso para tornar os espaços (que a princípio estavam destinados a setores administrativos) em salas de aula e um lugar para que os estudantes tenham a possibilidade de realizar atividades físicas. Essa situação pode agravar-se caso o orçamento permaneça no mesmo patamar ou diminua ainda mais, pois, devido à abertura de novos cursos, mais turmas estão sendo abertas e mais estudantes sendo matriculados. Assim, no campus, aumenta-se a demanda e diminuem-se os recursos, gerando dificuldades para maior acolhimento de servidores e estudantes e para o processo de integração educativa e inclusiva, no sentido de ofertar efetivamente uma educação de qualidade para os que ingressam nessa escola.

\section{Considerações Finais}

As políticas públicas como ações que podem intervir ou não na melhoria dos indicadores sociais dependem da caracterização do Estado e de sua atuação frente às demandas sociais. A ampliação de recursos financeiros na área social, incluindo a educação, com seus lentos avanços e suas persistentes limitações, revela determinantes políticos e econômicos que impõem o ritmo do desenvolvimento de um Estado mais voltado à universalização de políticas sociais.

A criação do Instituto Federal de Educação, Ciência e Tecnologia como política pública ampliou a oferta da educação profissional e a possibilidade de desenvolvimento econômico e social nas regiões em que foram implantados os campi. No entanto, as imposições da crise econômica e as decisões governamentais para combatê-la afetaram a disponibilidade de recursos financeiros para gastos, principalmente de capital, o que limitou o ritmo de reformas e a realização de novas instalações físicas. Como contraponto, os percentuais do PIB gastos com a dívida pública que consomem quase metade do orçamento público são mantidos.

É incontestável a necessidade de um equilíbrio entre receitas e despesas no orçamento público. Em períodos em que o crescimento econômico não evolui no ritmo esperado e os recursos tornam-se mais escassos é necessário fazer escolhas para identificar possibilidades de ajustes. No caso brasileiro, no contexto crise econômica estabelecida a partir de 2015, a área social foi afetada com cortes e contingenciamentos. A educação como um direito social compõe um rol de reivindicações sociais que devem fazer parte da ação do Estado voltado a uma política de desenvolvimento econômico vinculado ao desenvolvimento humano e social.

\section{Referências}

BRASIL. Constituição da República Federativa do Brasil de 1988. Nós, representantes do povo brasileiro, reunidos em Assembleia Nacional Constituinte para instituir um Estado Democrático, destinado a assegurar o exercício dos direitos sociais e individuais, a liberdade, a segurança, o bem-estar, o desenvolvimento, a igualdade e a justiça como valores supremos de uma sociedade fraterna, pluralista e sem preconceitos, fundada na harmonia social e comprometida, na ordem interna e internacional, com a solução pacífica das controvérsias, promulgamos, sob a proteção de Deus, a seguinte CONSTITUIÇÃO DA REPÚBLICA FEDERATIVA DO BRASIL. Diário Oficial da União, Brasília, 05 out. 1988. p. 1. 
A Implantação do Campus Campo Largo como Política Pública e as Implicações Orçamentárias como Sinalizadoras da Forma de Atuação do Estado

BRASIL. Lei $n^{\circ}$ 9.394, de 20 de dezembro de 1996. Estabelece as diretrizes e bases da educação nacional. Diário Oficial da União, Brasília, 23 dez. 1996. p. 27833. Disponível em: <http://www.planalto.gov.br/ccivil_03/leis/L9394.htm>. Acesso em: 22 fev. 2017.

BRASIL. Lei $\mathrm{n}^{\circ}$ 11.892, de 29 de dezembro de 2008. Institui a Rede Federal de Educação Profissional, Científica e Tecnológica, cria os Institutos Federais de Educação, Ciência e Tecnologia, e dá outras providências. Diário Oficial da União, Brasília, 30 dez. 2008. p. 1. Disponível em: <www.planalto.gov.br/ccivil_03/_ato2007-2010/2008/lei/l11892.htm>. Acesso em: 22 fev. 2017.

INSTITUTO FEDERAL DO PARANÁ. Plano de Distribuição Orçamentária 2016. Curitiba: IFP, 2016. Disponível em: <http://info.ifpr.edu.br/wp-content/uploads/PDO-2016-.pdf>. Acesso em: 11 mar. 2017.

INSTITUTO FEDERAL DO PARANÁ. Mapa Unidades. 2017. 1 fotografia. Disponível em: $<$ http://reitoria.ifpr.edu.br/wp-content/uploads/2009/03/mapa-unidades.png>. Acesso em: 08 mar. 2017.

INSTITUTO FEDERAL DO PARANÁ. Campus Campo Largo. Curitiba, s.d. Disponível em: <http://campolargo.ifpr.edu.br/menu-institucional/o-campus/>. Acesso em: 05 de mar. 2017.

INSTITUTO FEDERAL DO SUL DE MINAS GERAIS. IFSULDEMINAS disponibiliza as Planilhas de Investimento (Capital) e Custeio referente ao Orçamento 2015. Belo Horizonte, s.d. Disponível em: <http://www.ifsuldeminas.edu.br/index.php/pt/noticias/40062015-07-27-17-55-35>. Acesso em: 09 mar. 2017.

MELCHIOR, José Carlos de Araújo. O Financiamento da Educação no Brasil. São Paulo: EPU, 1987.

MINCATO, Ramone. Políticas Públicas e Sociais: uma abordagem crítica e processual. In: OLIVEIRA, Mara de; BERGUE, Sandro Trescastro (Org.). Políticas Públicas: definições, interlocuções e experiências. 2. ed. Caxias do Sul: Educs, 2012. p. 81-97. Disponível em: $<$ https://www.ucs.br/site/midia/arquivos/POLITICAS_PUBLICAS_EDUCS_EBOOK_2.pdf>. Acesso em: 01 mar. 2017.

OREIRO, José Luis. A Grande Recessão Brasileira: diagnóstico e uma agenda de política econômica. Estudos Avançados, São Paulo, v. 31, n. 89, p. 75-88, abr. 2017. Disponível em: <http://www.scielo.br/pdf/ea/v31n89/0103-4014-ea-31-89-0075.pdf>. Acesso em: 19 out. 2017.

PACHECO, Eliezer (Org.). Institutos Federais: uma revolução na educação profissional e tecnologia. Brasília: Fundação Santillana; São Paulo: Editora Moderna, 2011.

POGGI, Gianfranco. A Evolução do Estado Moderno: uma introdução sociológica. Tradução Álvaro Cabral. Rio de Janeiro: Zahar, 1981.

POULANTZAS, Nicos. O Estado, o Poder, o Socialismo. Tradução Rita Lima. 2. ed. Rio de Janeiro: Graal, 1985.

SALVADOR, Evilásio; TEIXEIRA, Sandra. Orçamento e Políticas Sociais: metodologia de análise na perspectiva crítica. Revista de Políticas Públicas (UFMA), São Luís, v. 18, n. 01, p. 15-32, jan./jun. 2014. 
A Implantação do Campus Campo Largo como Política Pública e as Implicações Orçamentárias como Sinalizadoras da Forma de Atuação do Estado

Simone Aparecida Milliorin possui graduação em Pedagogia pela Universidade Federal do Paraná (1998) e especialização em Psicopedagogia (2003) e Neurociência para Educadores (2011). Tem experiência na área de Educação. Atuou como professora e pedagoga em escolas da Rede Municipal de Educação de Campo Largo. Atualmente, é pedagoga no Instituto Federal do Paraná.

E-mail: simonemilliorin@yahoo.com 


\section{Editores do volume 7}

José Marcelino de Rezende Pinto - Universidade de São Paulo, São Paulo/SP, Brasil

Nalú Farenzena - Universidade Federal do Rio Grande do Sul, Porto Alegre/RS, Brasil

\section{Comitê Editorial}

José Marcelino de Rezende Pinto - Universidade de São Paulo, Brasil

Juca Gil - Universidade Federal do Rio Grande do Sul, Brasil

Theresa Adrião - Universidade Estadual de Campinas, Brasil

Ângelo Ricardo de Souza - Universidade Federal do Paraná, Brasil

Márcia Aparecida Jacomini - Universidade Federal de São Paulo, Brasil

\section{Conselho Editorial}

\section{Alejandro Morduchowicz}

Universidad Pedagógica, Provincia de Buenos Aires, Argentina

Fernanda Saforcada

Universidade de Buenos Aires, Argentina

Jacques Velloso

Universidade de Brasília, Brasil

João Monlevade

Senado Federal, Brasil

Jorge Abrahão de Castro

Instituto de Pesquisa Econômica Aplicada / IPEA, Brasil

Juca Gil

Universidade Federal do Rio Grande do Sul, Brasil

Lisete Regina Gomes Arelaro

Universidade de São Paulo, Brasil

Luis Carlos Sales

Universidade Federal do Piauí, Brasil

Luiz de Sousa Junior

Universidade Federal da Paraíba, Brasil

Luiz Fernandes Dourado

Universidade Federal de Goiás, Brasil

Magna França

Universidade Federal do Rio Grande do Norte, Brasil

Maria Beatriz Luce

Universidade Federal do Pampa, Brasil

Universidade Federal do Rio Grande do Sul, Brasil

Marcos Edgar Bassi

Universidade Federal do Paraná, Brasil

Maria Dilnéia Espíndola Fernandes

Universidade Federal de Mato Grosso do Sul, Brasil

\section{Nalú Farenzena}

Universidade Federal do Rio Grande do Sul, Brasil

Nelson Cardoso do Amaral

Universidade Federal de Goiás, Brasil

Nicholas Davies

Universidade Federal Fluminense, Brasil

Rosana Evangelista Cruz

Universidade Federal do Piauí, Brasil

Rosana Gemaque

Universidade Federal do Pará, Brasil

Robert E. Verhine

Universidade Federal da Bahia, Brasil

Romualdo Portela de Oliveira

Universidade de São Paulo, Brasil

Theresa Adrião

Universidade Estadual de Campinas, Brasil

Tristan McCowan

University of London, Reino Unido

Vera Jacob

Universidade Federal do Pará, Brasil

Vera Peroni

Universidade Federal do Rio Grande do Sul, Brasil

Vitor Henrique Paro

Universidade de São Paulo, Brasil

\section{Equipe editorial}

Apoio ao Comitê Editorial: Patrícia Balthazar Garcia

Diagramação, Revisão de português e normalização: Edson Leonel de Oliveira

Revisão de inglês: Ananyr Porto Fajardo 